\title{
Antennal transcriptome analysis of the chemosensory gene families in Carposina sasakii (Lepidoptera: Carposinidae)
}

\author{
Zhiqiang Tian, Lina Sun, Yanyan Li, Linfa Quan, Huaijiang Zhang, Wentao Yan, Qiang Yue and Guisheng Qiu*
}

\begin{abstract}
Background: The peach fruit moth, Carposina sasakii Matsumura (Lepidoptera: Carposinidae), poses a serious threat to a variety of fruits and causes significant economic loss owing to difficulties in its prevention and control. The olfactory sense is generally acknowledged to be a novel target for pest control. However, a systematic study of the olfactory genes expressed in C. sasakii has not been reported yet. Here, we reported the antennal transcriptome of C. sasakii using high-throughput sequencing and annotated the main chemosensory multi-gene families.
\end{abstract}

Results: In the chemosensory gene families, 29 odorant-binding proteins, 13 chemosensory proteins, 1 sensory neuron membrane protein, 52 odorant receptors, 8 ionotropic receptors and 11 gustatory receptors were annotated in the C. sasakii antennal transcriptome. The number of olfactory genes obtained in our transcriptome was consistent with that identified in other lepidopteran insects, confirming that we basically accomplished the annotation of the chemosensory genes of $C$. sasakii in the adult antennal transcriptome. All sequences were annotated and analyzed by BLAST (basic local alignment search tool), and some chemosensory genes with specific functions were named according to the BLAST results and phylogenetic trees. Based on the expression profile in the transcriptome and phylogenetic analysis, differentially expressed genes (DEGs) were analyzed in both male and female adults. Finally, fluorescence quantitative real-time PCR was used to identify the male-specific or female-specific chemosensory genes that were putatively related to odor detection and recognition. Moreover, expression levels of OR33 and PBP2 were significantly higher in males than in females, indicating that these genes may interact with sex pheromones. We found some conserved antennal IRs and GRs involved in detecting sugar compounds (GR2, GR5, GR6, GR8) and carbon dioxide (GR1), which were also identified based on phylogenetic analysis.

Conclusions: There are 114 putative chemosensory proteins expressed in C. sasakii identified in this study. The identification of these proteins will make the molecular mechanism of odor recognition accessible.

Keywords: Peach fruit moth, Antennal transcriptome, Olfactory gene, Expression profile

\section{Background}

The peach fruit moth, Carposina sasakii Matsumura (Lepidoptera: Carposinidae), is one of the most damaging borers of pome and stone fruits [1,2], such as apple, hawthorn, pear, jujube, peach, et al. Once the larvae of this insect bore into the young fruits, the pests deteriorate the quality of the fruits, then eat the pulp and release excreta into the fruits, ultimately resulting in significant economic

\footnotetext{
* Correspondence: gszbpest@163.com

Research Institute of Pomology, Chinese Academy of Agricultural Sciences, 98 South Street, Xinghai, Xingcheng 125100, Liaoning, China
}

losses. To avoid severe damage in production areas, the peach fruit moth is even listed as one of the important quarantine pests in some ports and markets and needs to be manually checked carefully whether or not the fruits are infested with it before shipment [3]. Due to difficulties in the prediction and control of peach fruit moth infestations, pesticides must be periodically employed based on previous ecological studies of the moth [4]. The peach fruit moth is highly elusive and has a long lifecycle with overlapping generations. The peach fruit moth has gradually been researched in different fields, such as physiology, pathology and toxicology [5]. However, long-term

(c) The Author(s). 2018 Open Access This article is distributed under the terms of the Creative Commons Attribution 4.0 International License (http://creativecommons.org/licenses/by/4.0/), which permits unrestricted use, distribution, and 
reliance on broad-spectrum chemical insecticides would easily caused pesticide resistance as a result of abuse or unreasonable pesticide application [6-8]. Furthermore, pesticide residues in fruits are harmful to human health and the environment. For these reasons, new methods to effectively prevent and control infestations of this pest must be explored. Some research has recognized that the chemoreception system of insects plays a crucial role in receiving signals, and this is not only suggest chemoreception system are responsible for identifying the signal source from host volatiles or pheromones but also regulate many aspects of insect biological behaviors, which is well established at locating food as well as oviposition, mating, and escaping predators $[9,10]$.

Therefore, an understanding of the olfaction mechanism may provide a good start to a better understanding of pest control strategies. At present, sex pheromones or other attractants are widely used for emergence forecasts, mass trapping and mating disruption of this pest in the fruit tree economy according to their ecological nature. However, the sex pheromone traps used for the peach fruit moth have much lower attractiveness than those used for other lepidopteran insect pests and, to some extent, do not even trap the peach fruit moth. In 1977, two sex pheromone compounds of C. sasakii were identified as the main component of Z-7-eicosen-11-one and the minor component of Z-7-nonadeoen-11-one $(20: 1)$ [11]. On the basis of the distinctive chemical properties of sex pheromones, lepidopteran sex pheromones are classified into two groups (type I and type II) according to the length of the chains and features of compound $[12,13]$. The sex pheromones of C. sasakii belong to type II accounting for $\sim 15 \%$ of all reported moth pheromones with typical characters of long-chain polyunsaturated hydrocarbons and the corresponding epoxides composed of C17-C25 [14]. However, activity of the second component, Z-7-nonadeoen-11-one, was not detected, and this species was not attracted by neither Z-7-eicosen-11-one nor Z-7-nonadeoen-11-one alone [15]. Therefore, much work is still needed to identify a novel attractant or technique as an alternative to sex pheromones. Additionally, insects are a vast group that interacts with varying levels of specificity, so the study on the molecular basis of olfaction will provide some new insight into key areas of olfaction research, and a combination of behavioral and molecular experiments described in prior studies can be used to screen countless volatile compounds and elucidate the recognition mechanism, and some of compounds may be also important or helpful to humans [16]. At the present stage, although the physiological [2], biochemical and morphological characteristics of $C$. sasakii antenna sensilla have been widely researched [17], the molecular biology of its antenna has not been well studied as of yet. The existing research on the sensilla located on the larval mouthparts and the adult antennae of $C$. sasakii shows that most of them are similar to the sensilla of other lepidopteran insects, but the sensilla of C. sasakii differ somewhat in number, external appearance and distribution compared to those of other lepidopterans [18]. Notably, there are 4 types of sensilla including sensilla gemmiformium, malformed sensilla chaetica, and sensilla auricillica II and III that exist only in female antennae [17]. Other research has shown that there are a number of sensilla trichodea and sensilla chaetica at the end of the abdomen [19]. Electroantennograms (EAGs) were recorded from adult $C$. sasakii. The results revealed that adults are able to respond to the 5 ester compounds from apple varieties, and female adults show a strong reaction to hexyl acetate [20]. Consequently, the identification of these functionally olfactory genes, in combination with other experiments, will provide insight into the fundamental molecular mechanisms of the processes involved in the olfactory system.

Odorant-binding protein (OBP) along with chemosensory proteins (CSPs) are regarded as the first step for the transportation of hydrophobic odorants in olfactory recognition [21]. It is supposed that the odorant molecules (ligands) are carried to the olfactory neurons by the OBPs and activate the olfactory receptors [22]. But compared with OBPs, studies have shown that CSPs may be involved in other physiological activities acting as carriers [23, 24]. For example, some CSPs promote the identification of sex pheromones and odorant signaling molecules [25-28], regenerate legs in the cockroach Periplaneta americana and affect the transformation of the Locusta migratoria manilensis from gregarious to solitary behavior $[29,30]$. What's more, sensory neuron membrane proteins (SNMPs) located in the dendritic membranes of pheromone-sensitive neurons are also essential for detecting pheromone [31, 32]. And ORs are responsible for detecting signals that are transmitted to the brain for further processing, however, later results showed that ORs are not evolutionarily conserved from insects to vertebrates [33-36]. Another receptors family encoding GRs are mainly used for taste or contact stimuli, which play an important role in host seeking behaviors in many insects [37-39]. Besides OR-based detection of odorants, IRs as a new insect chemosensory family have been proved to be involved in odor detection as well in recent discoveries [40]. IRs evolved from ionotropic glutamate receptors (iGluRs) are not related to insect ORs, while both IR- and OR-expressing olfactory sensory neurons (OSN) populations expressing the same receptor innervate the same spherical structures [41].

With the increasing maturation of next-generation sequencing (NGS), an increasing number of olfactory genes in insects have been widely verified by genomic and transcriptomic data. NGS is an effective and novel way to 
increase our understanding of the molecular mechanism of olfactory recognition in insects, especially in the Carposinadae family. However, hardly any olfactory-related genes have been studied in C. sasakii. Thus, the identification of olfactory-related genes will be helpful to further study the molecular mechanism of olfactory recognition.

In this study, we sequenced the antennal transcriptome of C. sasakii using Illumina HiSeq4000, assembled and analyzed the transcriptome data, and reported sets of putative OBPs, CSPs, SNMPs, ORs, GRs, and IRs. We identified the expression patterns of the olfactory genes via FPKM. Then, quantitative reverse transcriptase (qRT)-PCR experiments were conducted to investigate the adult tissue expression pattern of these DEGs in both sexes. These results may help reveal olfactory receptive mechanisms and lay the foundation for further studies of the olfactory system of C. sasakii.

\section{Methods}

\section{Insect rearing and antenna collection}

The larvae of $C$. sasakii used in the experiments were collected from the apple orchard of the Institute of Pomology, Chinese Academy of Agricultural Sciences (CAAS), Liaoning province (Latitude $40.6+1{ }^{\circ} \mathrm{N}$, Longitude $\left.120.73{ }^{\circ} \mathrm{E}\right)$, China. The insects were fed immature apples (Golden Delicious) picked in July, and newly emerged adults were reared on a $10 \%$ honey solution in climatic chambers $\left(25 \pm 1{ }^{\circ} \mathrm{C}, 70 \pm 5 \% \mathrm{RH}, 16: 8 \mathrm{~L}: \mathrm{D}\right.$ photoperiod) [2]. We speculated that $C$. sasakii reached sexual maturity when the pupa emerged because most of the insects began mating after 9 o'clock at night on the day of emergence, and a few mated 2-3 days later [42]. Therefore, the male and female moths were kept separately, apart from each other. Antennae were dissected under low light intensity when the male and female moths entered the dark period. Then, the antennae were frozen in liquid nitrogen and stored at $-80{ }^{\circ} \mathrm{C}$. The total number of antennae excised from males and females was 250 each.

\section{RNA extraction}

Total RNA was extracted from male and female antennae with TRIZOL reagent using the manufacturer's instructions (Invitrogen, Carlsbad, CA, USA). A nanodrop (IMPLEN, CA, USA), Qubit ${ }^{\oplus}$ RNA Assay Kit in Qubit $^{\oplus}$ 2.0 Flurometer (Life Technologies, CA, USA) and Agilent Bioanalyzer 2100 system (Agilent Technologies, CA, USA) were used to detect the purity, concentration and integrity of RNA samples, and RNA degradation and contamination were monitored on $1 \%$ agarose gels to ensure the quality of the samples used for transcriptome sequencing.

\section{cDNA library construction and Illumina sequencing}

First, a total amount of $3 \mu \mathrm{g}$ RNA per sample was used as input material for the RNA sample preparations.
Sequencing libraries were generated using the NEBNext Ultra $^{\text {Ts }}$ RNA Library Prep Kit for Illumina ${ }^{\oplus}$ (NEB, USA) following the manufacturer's recommendations. For the preferential selection of cDNA fragments 150 $200 \mathrm{bp}$ in length, the library fragments were purified with the AMPure XP system (Beckman Coulter, Beverly, USA). Then, $3 \mu$ l USER Enzyme (NEB, USA) was used with size-selected, adaptor-ligated cDNA at $37{ }^{\circ} \mathrm{C}$ for $15 \mathrm{~min}$ followed by $5 \mathrm{~min}$ at $95{ }^{\circ} \mathrm{C}$ before PCR. Then, PCR was performed with Phusion High-Fidelity DNA polymerase, Universal PCR primers and Index (X) Primer. At last, PCR products were purified (AMPure XP system), and library quality was assessed on the Agilent Bioanalyzer 2100 system.

\section{Sequence assembly and functional annotation}

To ensure the accuracy of sequence assembly and that clean reads were obtained, raw reads of the fastq format were first processed through in-house Perl scripts. In this step, clean data (clean reads) were obtained by removing reads containing adapters, reads containing poly- $\mathrm{N}$ and low-quality reads from raw data. At the same time, the Q20, Q30, GC content and sequence duplication level of the clean data were calculated. All downstream analyses were based on clean data with high quality reads. The left files (read1 files) from all libraries/ samples were pooled into one big left.fq file, and right files (read2 files) were pooled into one big right.fq file. Transcriptome assembly was accomplished based on the left.fq and right.fq using Trinity (v2.3.0) with min_kmer_cov set to 2 by default and all other parameters set to default values [43]. The annotation of the assembled sequences was conducted by BLASTn and BLASTx searches (E-value $<1 \mathrm{e}-5)$ against the non-redundant protein database. After the unigenes were obtained using KOBAS (Version 2.0) in KEGG Orthology, the amino acid sequence predicted by HMMER (E-value <1e-10) was blasted against the Pfam database to obtain unigene annotation information $[44,45]$. Then, the blast results were imported into the Blast2GO pipeline for $\mathrm{GO}$ annotations [46]. FPKM (fragments per kilobase per million reads) values calculated by RSEM (RNA-Seq by Expectation-Maximization) (Version: v1.3.0) with default parameters directly represented gene expression differences between different antennae. Prior to differential gene expression analysis, for each sequenced library, the read counts were adjusted by the edgeR program package through one scaling normalized factor. Differential expression analysis of two samples was performed using the DEGseq (2010) R package. The $P$ value was adjusted using the $q$ value. $Q$ value $<0.005$ and $\mid \log 2$ (fold change) $\mid>1$ was set as the threshold for significantly differential expression [47]. 
Verification of olfactory genes and phylogenetic analyses All of the candidate chemosensory genes (OBPs, CSPs, SNMPs, ORs, GRs and IRs) and their open reading frames (ORFs) were manually verified by BLASTx and ORF Finder in the National Center of Biotechnology Information (NCBI). Moreover, the sequences of contigs with serious errors (mainly insertions/gap/deletions in homopolymer regions) were removed. Transmembrane domains of ORs, IRs, and GRs were predicted using the default parameter of TMHMM2.0 and TMPred, and the N-terminal signal peptide of the candidates OBPs and CSPs were predicted by SignalP4.0 [48]. The amino acid sequences of chemosensory genes identified in the $C$. sasakii antennal transcriptome are listed in Additional file 1.

For verification of the annotation of the candidate chemosensory genes and identification of orthologs, phylogenetic analyses were conducted among C. sasakii and other Lepidoptera species with close genetic relationships. For the selected insects, their transcriptomes and olfactory gene functions have been well studied, or their genomes have been published. In addition, since IRs are relatively conserved among different insects, IR sequences from non-lepidopteran species were also selected for phylogenetic analysis in the data set. The available amino acid sequences of chemosensory genes identified in different species were downloaded from the NCBI database to construct the phylogenetic tree. Amino acid sequences were aligned using the Clustalw method by Mega v7.0 [49]. The Maximum Likelihood Tree Method with the JTT model, uniform rates, partial deletion, Nearest-Neighbor-Interchange heuristic method and default automatic NJ/BioNJ was conducted by MEGA v7.0 and subsequently viewed and graphically edited by FigTree (version 1.4.3). To ensure the accuracy of the tree structure, the tree was created with 1000 replicates. The protein sequences of chemosensory proteins used for building phylogenetic trees are listed in Additional file 2.

\section{DEG analysis based on the FPKM value}

To mine the data of the differential expression of chemosensory genes in the transcriptomes, we analyzed the expression of all chemosensory genes in the male and female antennae using FPKM (reads per kilobase of exon model per million mapped reads) values. First, the chemosensory genes in the female antennae were chosen as the reference for expression profiling analysis between male and female antennae. Then, the unigene expression levels were calculated based on the FPKM method. In addition, the corrected $P$-values were used to identify differentially expressed genes using the Benjamini-Hochberg method [50]. The FDR (False Discovery Rate) is considered to be a key indicator in multiple hypothesis testing for screening different genes. To normalize antennal expression levels of candidate chemosensory genes based on the FDR we used $\log 2$ to express the fold change. The parameter for filtering the significant differential expression was set to FDR $\leq 0.01$ and FC (Fold Change) $\geq 2$.

Finally, a total of 27 genes including 14 ORs (CsasOR3, 4, 8, 17, 21, 24, 30, 31, 33, 34, 41, 46, 48 and 49), 3 CSPs (CsasCSP1, 5 and 12), 1 GRs (CsasGR8), 8 OBPs (CsasOBP7, 9, 12, 15, 19, 21, CsasGOBP1 and CsasPBP2) and 1 SNMP (CsasSNMP2) were selected for investigation. Most of them (20) were selected due to their significantly different expression in male and female antenna based on the DEG analysis, and a few of them (7) were selected as genes of interest due to their extremely high or low expression based on their FPKM value.

\section{qRT-PCR verification for DEGs}

Fluorescence quantitative real-time PCR was performed to verify the expression of candidate differential expression chemosensory genes. Different tissues including the head (exclude antennae, 50), thorax (30), abdomen (30), foot (30), wing (30), and antennae (250) were collected from both male and female adults. The extraction of total RNA followed the methods described above. The cDNA was synthesized from total RNA using the Prime ScriptRT Reagent Kit with gDNA Eraser to remove gDNA (No. RR047A; TaKaRa, Shiga, Japan). Gene-specific primers were designed using Primer3 (http://bioinfo.ut.ee/primer3-0.4.0/) (Additional file 3). Then, all of the differential genes and four reference genes including actin, 18S rRNA, elongation factor 1-alpha $(\mathrm{EF} 1 \alpha)$, and ribosomal protein L40 were identified and selected from the antennal transcriptome; Then, the efficiency of amplification was analyzed to verify the different tissues of males and females (Additional file 3). According to the result, we selected actin and EF1 $\alpha$ as reference genes for qPCR (Additional file 3). The Bio-Rad CFX96 PCR System (Hercules, CA, USA) and SYBR Premix ExTaq ${ }^{\text {тм }}$ II (No. RR820A; TaKaRa) were used for the PCR reaction under a three-step amplification process of $95{ }^{\circ} \mathrm{C}$ for $30 \mathrm{~s}$, followed by 40 cycles of $95{ }^{\circ} \mathrm{C}$ for $5 \mathrm{~s}, 60{ }^{\circ} \mathrm{C}$ for $30 \mathrm{~s}$, and 65 to $95{ }^{\circ} \mathrm{C}$ in increments of $0.5{ }^{\circ} \mathrm{C}$ for $5 \mathrm{~s}$ to generate the melting curves. Furthermore, the qPCR amplification products were run on a gel to confirm that the size of the qPCR products were consistent with the predicted size.

In the analysis of the relative fold change of these all DEGs in different tissues, the female head (without antennae) sample was used as the calibrator. Two reference genes were used for calculating and normalizing the target gene expression and correcting for sample to sample variation, then means and standard errors were obtained based on three technical replicates and biological replicates. The relative expression levels were calculated according to the comparative $2^{-\Delta \Delta \mathrm{Ct}}$ method.

Data (mean $\pm \mathrm{SE}$ ) from various samples were subjected to one way nested analysis of variance followed by a 
least significant difference test for mean comparison using SPSS 17.0 (IBM, Chicago, IL, USA).

\section{Results}

\section{Transcriptome sequencing}

To identify olfactory genes, we separately completed the transcriptome sequencing of male and female antennae. Approximately 32.2 and 32.9 million clean reads were generated in male and female antennae, respectively. The mapped ratios (mapped reads as a percent of clean reads) were 75.48 and $74.41 \%$ when the clean data was aligned with the Transcript or Unigene, respectively. In addition, the Q30 base percentage exceeded $92.70 \%$. After the adapters and low-quality raw sequences were filtered out and the reads from both the male and female antennae were assembled into a single transcriptome, 66,290 unigenes with an N50 of 1449 bp were generated. The number of unigenes longer than $1 \mathrm{~Kb}$ was 11,997 , which was listed at Additional file 4: Figure S1 and Table 1. The raw reads were deposited at the National Center for Biotechnology Information (NCBI) - Sequence Read Archive (SRA) database with the submission number SRR5431770 and SRR5431771. In addition, all contigs have been submitted to the Transcriptome Shotgun Assembly (TSA) sequence database at NCBI with the accession numbers GFQL00000000.

\section{Functional annotation of the unigenes in C. sasakii}

We used the unigenes assembled in the transcriptome as queries in BLASTx searches of the NCBI non-redundant protein (NR), Swiss-Prot, COG (Clusters of Orthologous Groups), KOG (euKaryotic Orthologous Groups), eggNOG, Pfam (Protein family), GO (Gene Ontology) and KEGG (Kyoto Encyclopedia of Genes and Genomes) databases (Table 2). When the BLASTx parameter E-value was less than 1e-5, 20,006 unigenes (30.18\%) were annotated in the above databases. The highest two percentages of unigenes annotated were found in the NR and eggNOG databases and were almost equivalent, with 28.55 and $27.82 \%$, respectively. Moreover, the COG database had the lowest

Table 1 Summary of assembled transcript and unigenes

\begin{tabular}{lll}
\hline Length Range(bp) & Transcript & Unigene \\
\hline 200-300 & $36,802(27.88 \%)$ & $29,614(44.67 \%)$ \\
$300-500$ & $25,046(18.98 \%)$ & $15,225(22.97 \%)$ \\
500-1000 & $24,612(18.65 \%)$ & $9454(14.26 \%)$ \\
$1000-2000$ & $23,159(17.55 \%)$ & $6433(9.70 \%)$ \\
2000+ & $22,366(16.95 \%)$ & $5564(8.39 \%)$ \\
Total Number & 131,985 & 66,290 \\
Total Length & $146,824,982$ & $47,364,163$ \\
N50 Length & 2135 & 1449 \\
Mean Length & 1112.44 & 714.5 \\
\hline
\end{tabular}

Table 2 Functional annotation of the unigenes in different databases

\begin{tabular}{llll}
\hline Annotated Database & unigene & $300-1000 \mathrm{bp}$ & $\geq 1000 \mathrm{bp}$ \\
\hline COG_Annotation & 5673 & 1556 & 3271 \\
GO_Annotation & 10,219 & 3073 & 5505 \\
KEGG_Annotation & 7699 & 2306 & 4225 \\
KOG_Annotation & 11,762 & 3317 & 6791 \\
Pfam_Annotation & 13,081 & 3736 & 7781 \\
Swissprot_Annotation & 9647 & 2674 & 5893 \\
eggNOG_Annotation & 18,441 & 6037 & 9224 \\
nr_Annotation & 18,925 & 6370 & 9425 \\
All_Annotated & 20,006 & 6779 & 9481 \\
\hline
\end{tabular}

number of annotated unigenes with 5673 unigenes (8.56\%). $\mathrm{GO}$ analysis showed that most of the unigenes (approximately $84.58 \%$ ) were not annotated in a GO category.

GO was used to divide the differentially expressed unigenes, and all of the unigenes were divided into three categories (molecular function, cellular component, or biological process) according to the biological processes and functional annotations (Additional file 4: Figure S2). In the biological process terms, cellular, single-organism and metabolic occupied the majority of both differentially expressed unigenes and all unigenes. In the cellular component terms, cell, cell part and organelle were the most abundant for all unigenes. However, membrane, cell and cell part were the most abundant for the differential unigenes. In the molecular function category, binding, catalytic activity and transporter activity had a huge preponderance of both of them.

\section{Candidate genes related to transport odorant molecules Odorant-binding protein}

A total of 29 OBPs including PBPs and GOBPs were identified using the BLASTx program (Additional file 5: Table S1). The sequence identities of the OBPs with other Lepidopteran insects ranged from 40 to $96 \%$ in the NCBI database, with an average of $67 \%$. The further alignment of the amino acid sequences showed that 19 OBPs belonged to the classical OBP subgroup with the motif "C1-X15-39-C2-X3-C3-X21-44-C4-X7-12-C5-X8-C6"

(where $\mathrm{X}$ represents any amino acid) [51-53] (Additional file 4: Figure S3). The remaining 9 OBPs (OBP4, OBP5, OBP8, ОВР9, ОВР13, ОВР17, ОВР19, ОВР22, ОВР23) were not only outside the range of the plus- $\mathrm{C}$ owing to the lack of complete 6 conserved cysteines but also the minus- $C$ subgroups because of noncompliance with their motif. In addition, the classical OBPs that fit the motif encoded complete open reading frames (ORFs) with a sequence length $>400 \mathrm{bp}$, while 5 OBPs (OBP1, OBP4, OBP9, OBP20, OBP22) had no signal peptides. 
A phylogenetic tree was constructed using the sequences from four lepidopteran species (Fig. 1). The phylogenetic analysis demonstrated that the lepidopteran PBP and GOBP sequences were highly conserved and clustered into three lineage-specific clades according to their different functions. However, other OBPs showed an extremely divergent trend. Finally, three GOBPs and PBPs were identified, while GOBP3 did not cluster so closely with other GOBP1s/GOBP2s. Further homology matrix analysis indicated that the sequence identity of GOBP3 among each GOBP1 was much higher, ranging from 56.6 to $72.5 \%$ and sharing an average of $65.2 \%$ identity.

\section{Chemosensory proteins}

In our study, 13 CSPs were identified in C. sasakii. All 13 CSPs have four highly conserved cysteine residues and fit the "CSP sequence motif", C1-X6-8-C2-X16-21-C3-X2-C4, where $\mathrm{X}$ represents any amino acid [54]. Furthermore, all CSPs presented a complete ORF (https://www.ncbi.nlm.nih. gov/orffinder/) and signal peptide (http://www.cbs.dtu.dk/ services/SignalP/) (Additional file 5: Table S2). At last, the multiple alignment (except CSP3 due to its longer sequence than that of other CSPs) was generated based on the characteristics of 4 cysteines and approximately 100-200 residues [55] (Fig. 2).

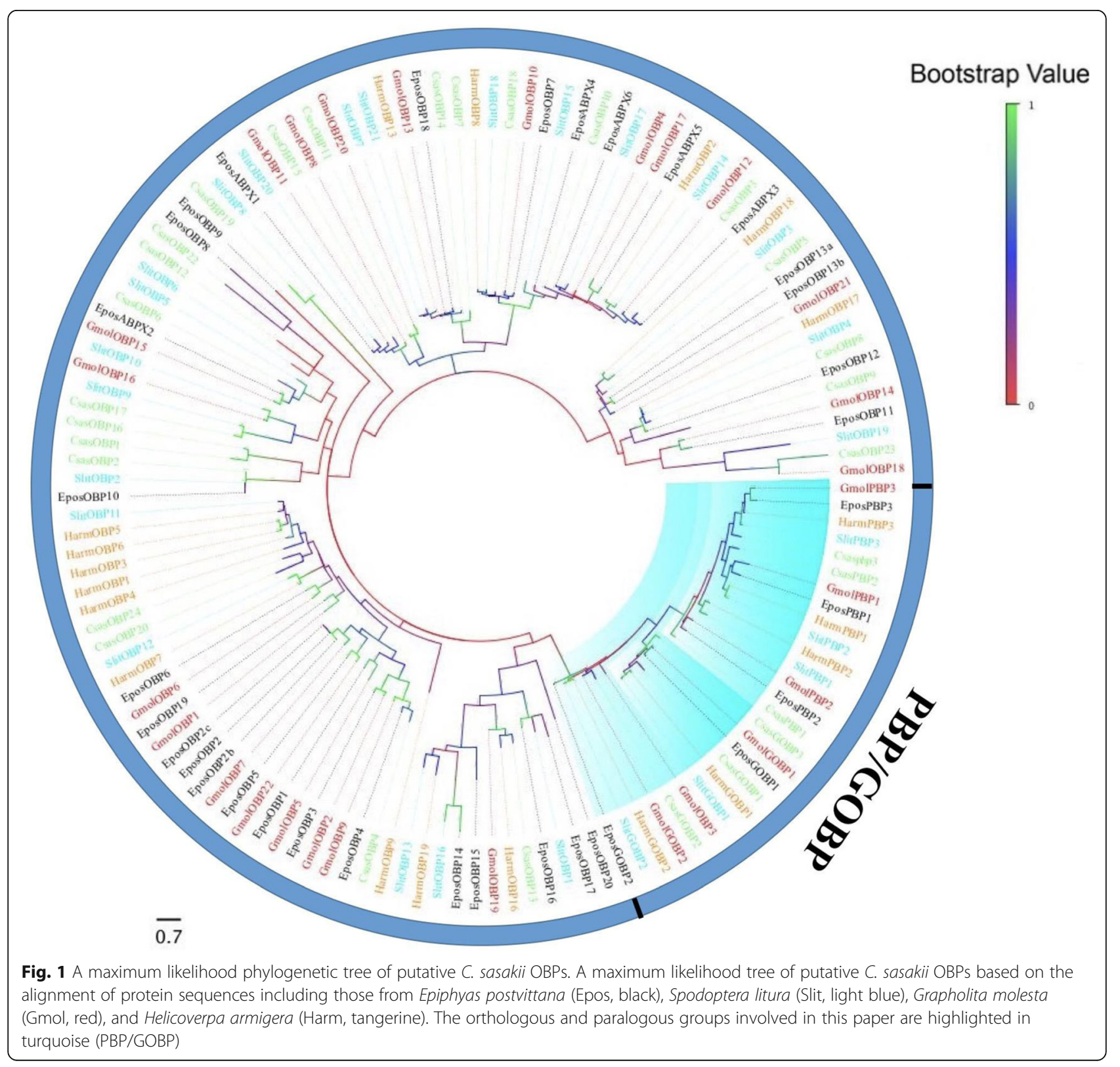




\begin{tabular}{|c|c|c|}
\hline & $\begin{array}{ll}\text { C1 } & \text { C2 } \\
\Delta & \Delta\end{array}$ & \\
\hline CSP1 & $\ldots \ldots \ldots \ldots \ldots \ldots \ldots$ MFIRCM.. VIAVLVVANAMTQAVNDPSTDDGTMGELDKILTNRAVMRRILSGVLVESKGDFGSAFLKMLAFQ & 69 \\
\hline $\operatorname{CSP} 2$ & $\ldots \ldots \ldots \ldots \ldots \ldots$ MSGSLQRFLGGILMVWVACATAQVVDDPSTDNGRMQDLDRVIVNNQIMKYILKGVILEGEODKRGNFMRMLAFQ & 74 \\
\hline $\operatorname{csp} 4$ & 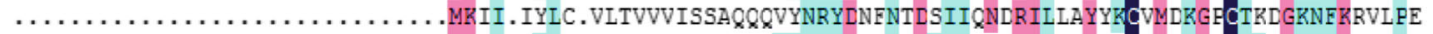 & 67 \\
\hline CSP5 & MTVYNVLSRLSTGTPWLGVERISPILILSINMRLL. ILVALSCVAFACGRPASTYTDKWDHNVDEILESNRILKAYVEGLMDRGRCTFDAKELRETLFD & 99 \\
\hline $\operatorname{csp} 6$ & 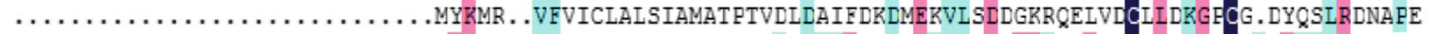 & 67 \\
\hline $\operatorname{csp} 7$ & 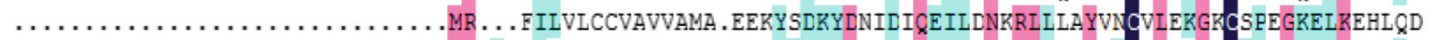 & 65 \\
\hline $\operatorname{CSP} 8$ & 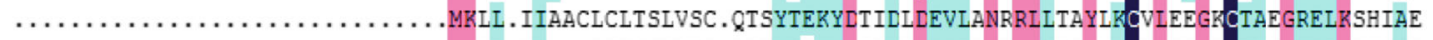 & 67 \\
\hline $\operatorname{csp9}$ & $\ldots \ldots \ldots \ldots \ldots \ldots \ldots \ldots$ MRVI.VV $\ldots$ LIFFIGVVYG.DDTYTTKYDGIDLDEILANERILNGYVKGIIETGEGTFDGKELRKNIFD & 64 \\
\hline CSP10 & 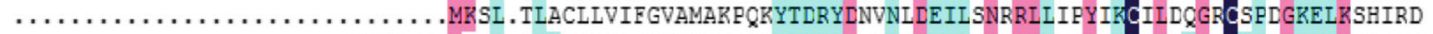 & 68 \\
\hline CSP11 & $\ldots \ldots \ldots \ldots \ldots \ldots$ MFRNLVKMNLI. LVLCLMVIHFVVAD.EEQYTDRYDNLNVDEI INNRRIFEGYMKGLINRGROTPEGKE IRAHIID & 74 \\
\hline CSP12 & 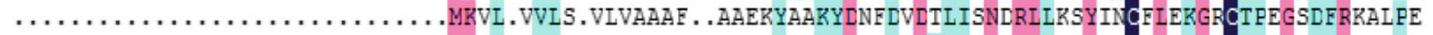 & 65 \\
\hline $\operatorname{csP13}$ & 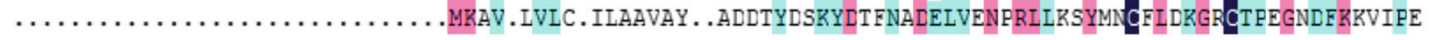 & 65 \\
\hline & & \\
\hline CSP1 & 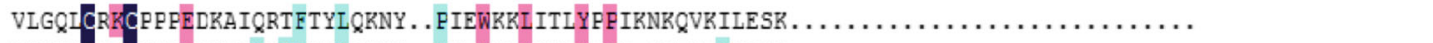 & 122 \\
\hline $\operatorname{csp} 2$ & 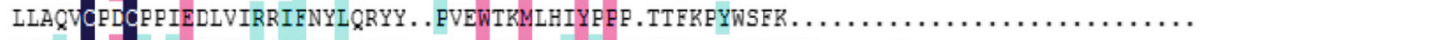 & 126 \\
\hline $\operatorname{csp} 4$ & TISTA dAROTTKCKAVVRKMILGIRERS . EPRFLEILDKYDPEQYNREALYTFLLT $\ldots \ldots G Q \ldots \ldots \ldots \ldots \ldots \ldots$ & 124 \\
\hline CSP5 & ALENDGSKOTGKQREGSDKVITHLINKR . . FDLWKEISSKYDFRDIYQHRYKNRIES $\ldots \ldots$ IRGKS $\ldots \ldots \ldots \ldots \ldots \ldots$ & 159 \\
\hline $\operatorname{csp} 6$ & 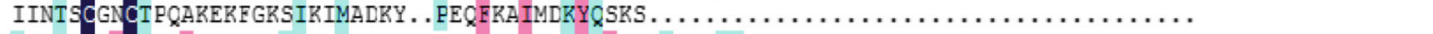 & 110 \\
\hline $\operatorname{csp} 7$ & AIETGCXKOTEACERGAYQVIEHLIKNE. . RDIWKEMADKFDEEGKWRKKYEDRARERGIEIFER $\ldots \ldots \ldots \ldots \ldots \ldots$ & 128 \\
\hline CSP8 & 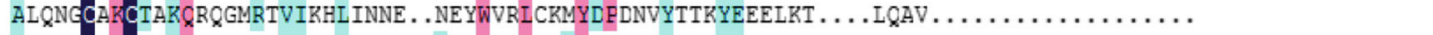 & 126 \\
\hline $\operatorname{cspg}$ & AMQNDdAKOSERQRHGSDQVMEYIIDHR . . FDDWTKLEAKYHSDGSYKSKYEERKKA . . . . AERKEVSRDEETTGNTVEDVQPN & 142 \\
\hline CSP10 & ALENN GSKOTEVQRNGTRRVIGHIINNE . VDYWNQITAKYDETHQETRKYENELRQ $\ldots$ VKH $\ldots \ldots \ldots \ldots \ldots \ldots$ & 126 \\
\hline CSP11 & AMHTZ GKKOTPRQRKAARQVVRYIRDNDKMQHYWNDIKRLYDEDNKYKDTYEPFFAS $\ldots \ldots$ DD $\ldots \ldots \ldots \ldots \ldots$ & 133 \\
\hline CSP12 & AISTTdAKOTERQQNNIRKVIKAIQQRH. . FRSWDEIVKRNDETGKYTADFEREVNG $\ldots \ldots N \ldots \ldots \ldots \ldots \ldots \ldots$ & 121 \\
\hline CSP13 & AVRTSQARGSGPQRQLVRKVIKAFQARL . FQEWWSEIVKKEDENGQYTVEFNRFVAG $\ldots \ldots$ SD $\ldots \ldots \ldots \ldots \ldots \ldots$ & 122 \\
\hline
\end{tabular}

\section{Sensory neuron membrane proteins (SNMPs)}

Only one sensory neuron membrane protein (SNMP) with a complete ORF was identified in our transcripts, and was termed SNMP2 based on the BLASTx and cluster analysis results. What's more, the length of ORF (SNMP2) was approximately $1500 \mathrm{bp}$, indicating it was nearly full-length genes (Additional file 5: Table S3). In addition, CsasSNMP2 was more conserved across other SNMP2 variants, with 67 and $72 \%$ amino acid identity, respectively. As expected, CsasSNMP2 grouped together with other SNMP2 orthologues (Fig. 3).

\section{Identification of receptor-encoding genes Odorant receptors}

In this study, 52 ORs were identified in the male and female transcriptome, which was more than the number of ORs identified in Heortia vitessoides (35 ORs) [56]. In addition, 33 of the ORs were likely full-length OR genes because the length of the portion encoding the proteins was more than 389 amino acids. Of these ORs, the identity of the best BLAST match in the NR database ranged from 35 to $91 \%$. Notably, Orco identified in the C. sasakii transcriptomes shared the highest identity, similar to Orco in Conogethes punctiferalis [57]. In addition, the transmembrane domains were predicted in view of the sequence characteristics of the ORs. The results indicated that all of them contained 2-10 transmembrane domains (Additional file 5: Table S4).
The maximum likelihood tree was subsequently created by Mega 7.0. To guarantee the reliability and validity of the phylogenetic tree, all of the ORs that encoded proteins were used to build the ML tree based on the multiple protein sequence alignments (Fig. 4). The highly conserved co-receptor (Orco) formed a group indicated by a light purple background, and the identity ranged from 83 to $88 \%$. In the interest of exploring the sex pheromone-binding receptors in C. sasakii, some sex pheromone receptors, such as $M$. sex [58], C. pom [59], B. mor [60], E. pos [61], and H. vir [62], whose sequences were derived from what has been reported in the NCBI database and has been widely studied, were used to construct the phylogenetic tree. The phylogenetic tree of the pheromone receptors (PRs) with the light green background, indicated that CsasOR3, CsasOR8, CsasOR21, and CsasOR33 were clustered with PRs from other moths. Comparison of the sequences of all identified olfactory receptors in the ML tree revealed a very high degree of diversity, with $\mathrm{PR}$ protein identities of $26-98 \%$. These results confirmed that PRs are highly divergent in lepidopteran insects.

\section{lonotropic receptors}

Eight candidate IRs were identified in the C. sasakii antennal transcriptomes. Some of the conserved IR genes including IR8a, IR21a, IR41a, IR76b and IR75 were present in our transcriptome data. These genes have also been identified in other lepidopteran species and some 


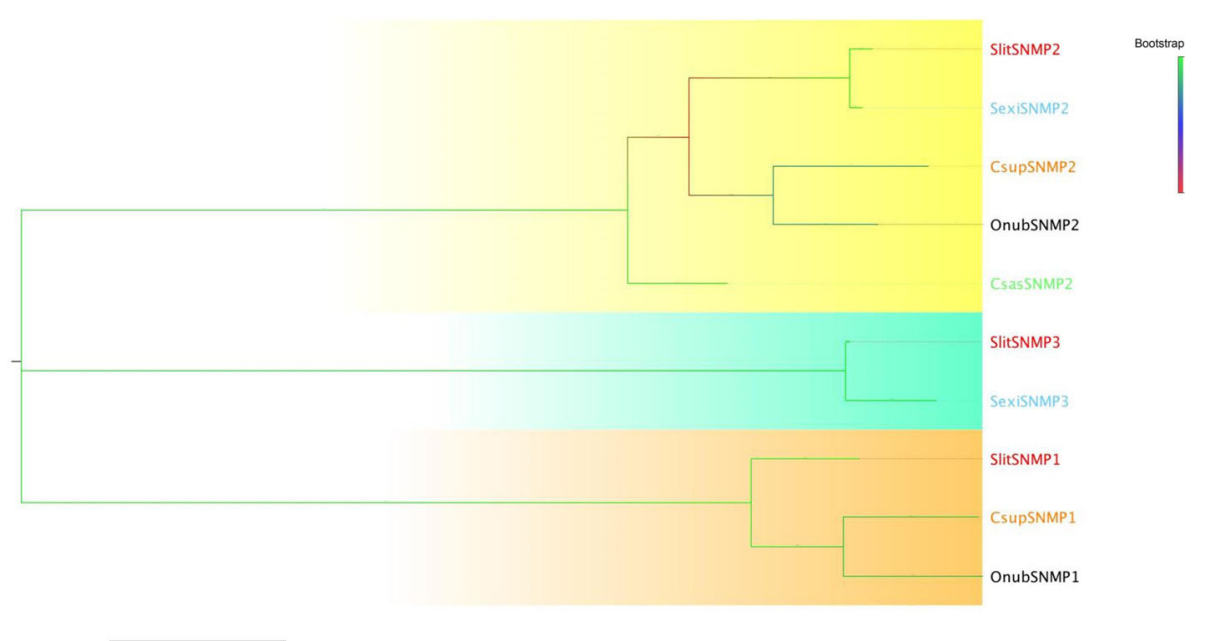

Fig. 3 A maximum likelihood phylogenetic tree of putative C. sasakii SNMPs. A maximum likelihood phylogenetic tree of putative C. sasakii SNMPs based on the alignment of protein sequences including those from Spodoptera litura (Slit, yellow), Ostrinia nubilalis (Onub, black), Spodoptera exigua (Sexi, turquoise), and Chilo suppressalis (Csup, tangerine). ML analysis was conducted using MEGA (v7.0)

of them (IR8a and IR76b) are classified as co-receptors, as well as necessary for olfactory responses [63]. Most of the IRs encoded longer ORFs (exceeding $1600 \mathrm{bp}$ except IR7d) than ORs with an average of $1834 \mathrm{bp}$. The transmembrane domains of IRs ranged from 0 to 8 (Additional file 5: Table S5). To further distinguish putative IRs from the transcriptome of C. sasakii, all of the IRs in our transcriptomes were aligned with IRs from Drosophila melanogaster, Cydia pomonella and Epiphyas postvittana by Mega software (v 7.0) for phylogenetic analysis. In the phylogenetic analyses, the IRs identified in our transcriptomes were clustered into the different clades of the conserved IRs (Fig. 5). For example, the IR41a group contained CpomIR41a.1, CpomIR41a.2 and EposIR41a. CsasIR21a was located in the clade of the IR21a group, IR8a group, IR75 group, and IR76b group, which are labelled with blue, pink and red circles, respectively. Finally, we named the CsasIRs based on the results of the phylogenetic tree. Compared to other conserved IRs including IR84a, IR100a, IR20a and 47a widely found in other species, fewer IRs were identified in C. sasakii.

\section{Gustatory receptors}

A total of 11 candidate GR transcripts were identified in both male and female $C$. sasakii transcriptomes with 2-9 transmembrane domains (Additional file 5: Table S6). This result was a little less than that in other Lepidoptera insects, such as Athetis dissimilis [64]. However, only four of them (GR2, GR3, GR9 and GR6) encoded an ORF longer than $1000 \mathrm{bp}$. The phylogenetic tree was used to classify the functions of GRs in C. sasakii transcriptomes using the GR genes identified in other insects (Fig. 6). GR2, GR5, GR6 and GR8 were clustered with the members of the candidate sugar detection GR subfamily. GR1 formed a clade with $\mathrm{CO}_{2}$ receptors from Helicoverpa armigera, Epiphyas postvittana and Bombyx mori Linnaeus. The bitter receptors included GR9 and GR4.

\section{Differentially expressed gene (DEG) analysis}

Gene expression levels of all chemosensory genes based on the FPKM value in $C$. sasakii were represented in Additional file 6: Figures S2-S7. The expression levels of OBPs showed that 5 OBPs (OBP9, 15, 21, GOBP1, PBP2) were mainly expressed in male antennae and that 2 OBPs (OBP7, OBP19) were highly expressed in female antennae. Only one of the CSPs, SNMPs and GRs was highly differentially expressed between male and female antennae. Meanwhile, the analysis of ORs showed that Orco had the highest expression level of ORs, but there was no difference in its expression between the male and female transcriptome. In addition, 3 ORs (OR31, OR33, OR41) were expressed at significantly higher levels in male antenna than in female antenna, whereas 8 ORs (OR4, OR17, OR24, OR30, OR34, OR46, OR48, OR49) showed the opposite result. In addition, none of the IRs showed a drastic difference in expression between females and males. The expression levels of all candidate GR transcripts were extremely low (Maximum FPKM value <4).

\section{Tissue-specific and sex-specific expression of candidate genes}

To better understand and validate the functional role of candidate DEGs in the different tissues from male and female adults, we investigated the expression patterns 


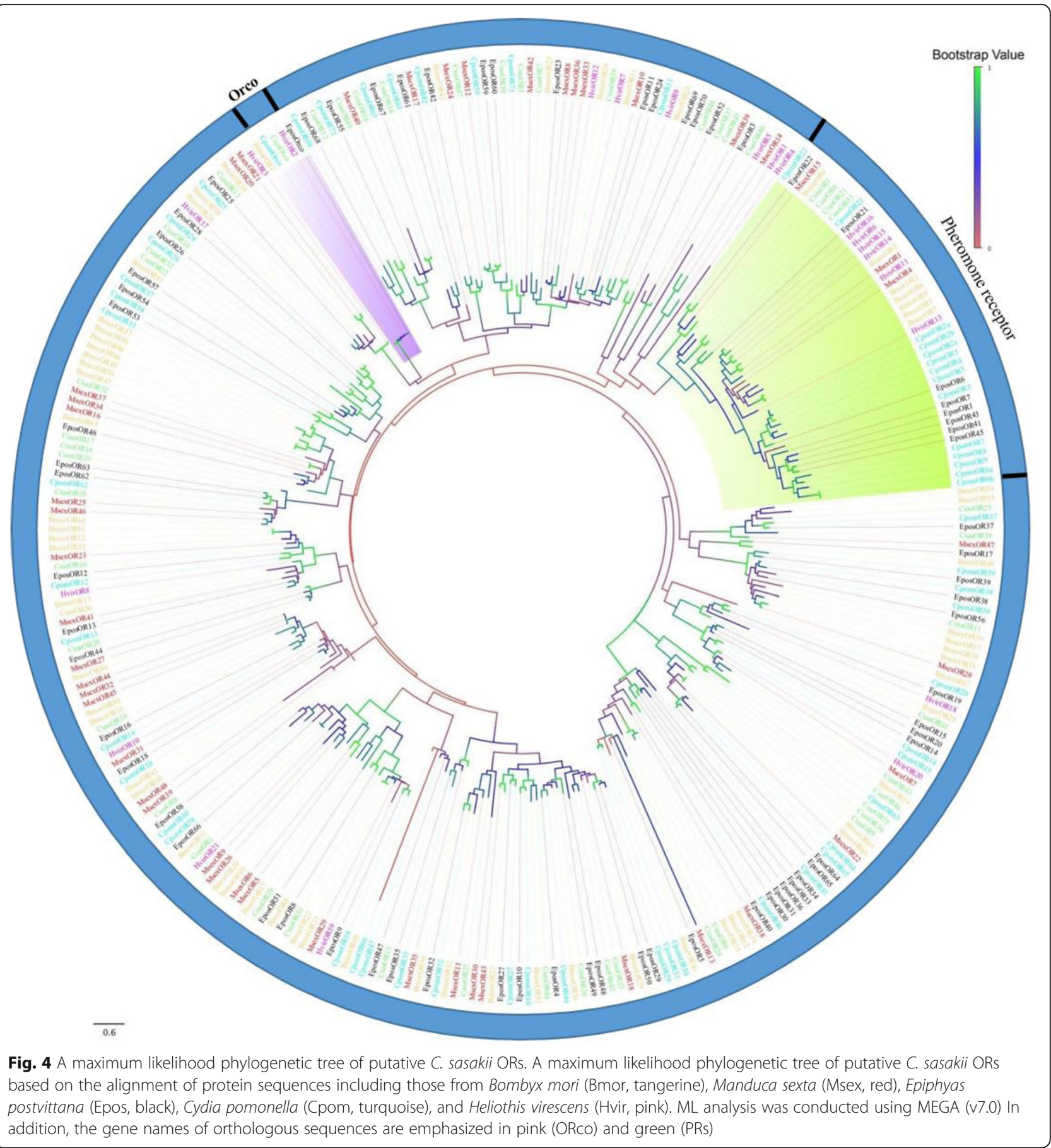

of these genes via fluorescence quantitative real-time PCR (Fig. 7).

OBP7 was specifically expressed in both female and male antennae but was expressed at significantly higher levels in males. OBP9, OBP15, CSP1 and CSP12 were expressed in other organs besides the antennae in both sexes, but these genes were most abundantly expressed in the abdomen, suggesting a ubiquitous role in C. sasakii.
GOBP1, GOBP3 and PBP2 were expressed at extremely significantly higher levels in male antenna than in female antenna, and there was little expression of these genes in other tissues. In addition, OBP12 was more highly expressed in the wings than in the antenna. The results for the 14 ORs showed that some of them were expressed not only in the olfactory organs but also in the non-olfactory organs; For instance, OR4 was widely 


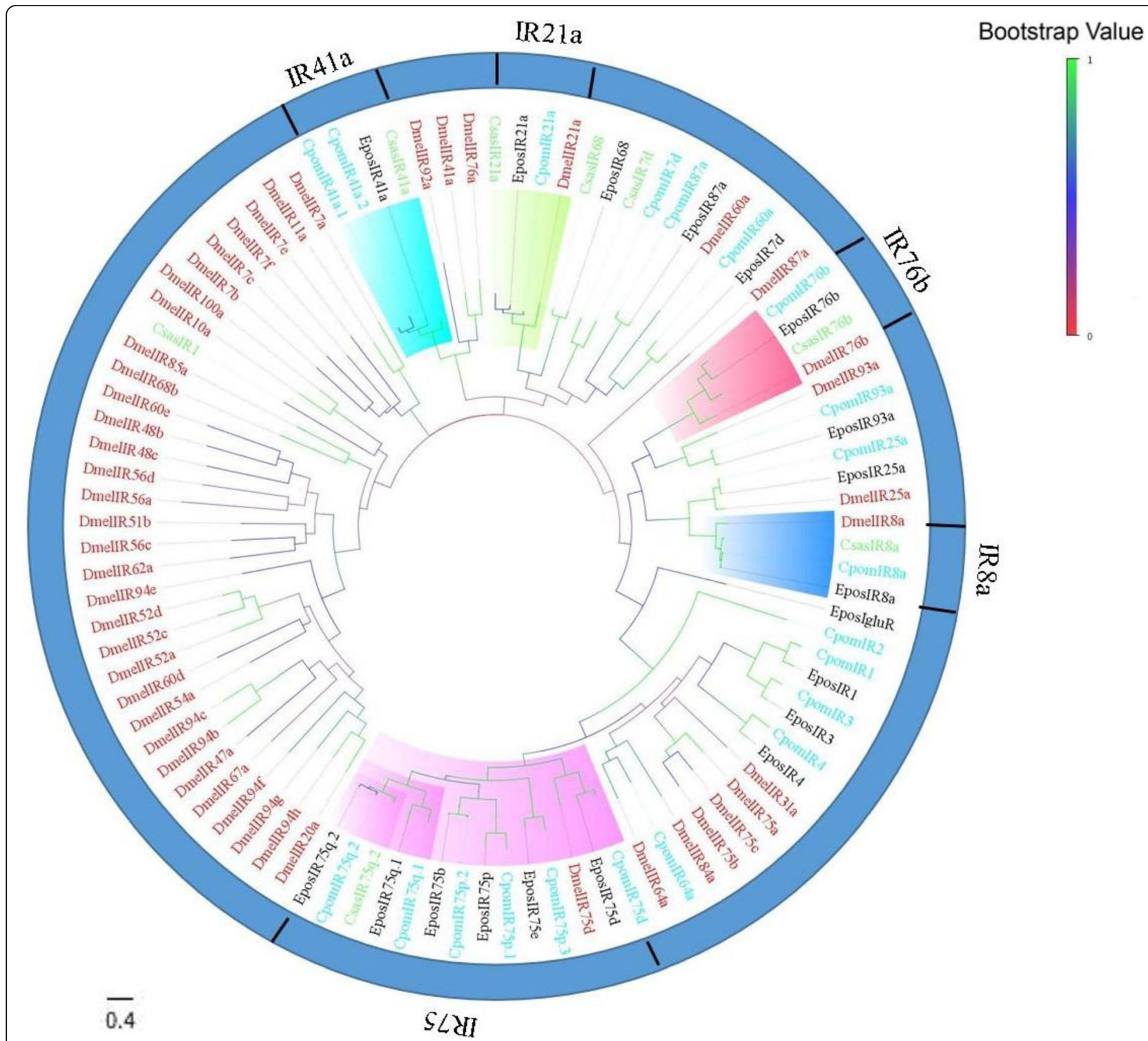

Fig. 5 A maximum likelihood phylogenetic tree of putative C. sasakii IRs. A maximum likelihood phylogenetic tree of putative C. sasakii IRs based on the alignment of protein sequences including those from Drosophila melanogaster (Dmel, red), Epiphyas postvittana (Epos, black) and Cydia pomonella (Cpom, turquoise) IRs. ML analysis was conducted using MEGA (v7.0). In addition, the gene names of orthologous sequences are emphasized in pink (IR75), turquoise (IR41a), blue (IR8a), green (IR21a) and red (IR76b)

distributed in the tissues examined in our study, and, to a certain extent, 5 ORs (OR17, OR33, OR34, OR41 and OR46) were detected in the wings, particularly in the wings of male adults. However, the expression levels above ORs were significantly higher in the antenna than those in the external genitalia. The expression of OR3 and OR41 was not significantly different between male and female antenna. The expression levels of 9 ORs (OR4, OR17, OR21, OR24, OR34, OR46, OR48, OR49 and GR8) were significantly higher in female antennae than those in male antennae. In addition, 4 ORs (OR8, OR30, OR31 and OR33) were significantly overexpressed in the male antenna compared to those in the female antenna.

\section{Discussion}

Prior to our study, the majority of research on C. sasakii was concentrated in the fields of biology and ecology $[3,17,42]$. In recent years, studies on olfactory proteins have increased gradually due to the vital role of olfactory proteins in insects. Our studies will provide novel ideas for population control methods as well as facilitate further study on olfaction in C. sasakii.

Based on the BLASTx and GO terms analyses, gene transcripts derived from 114 olfactory genes encoding putative olfactory proteins including OBPs, CSPs, SNMP, ORs, GRs and IRs were identified in the transcripts of male and female C. sasakii. These results were similar to 


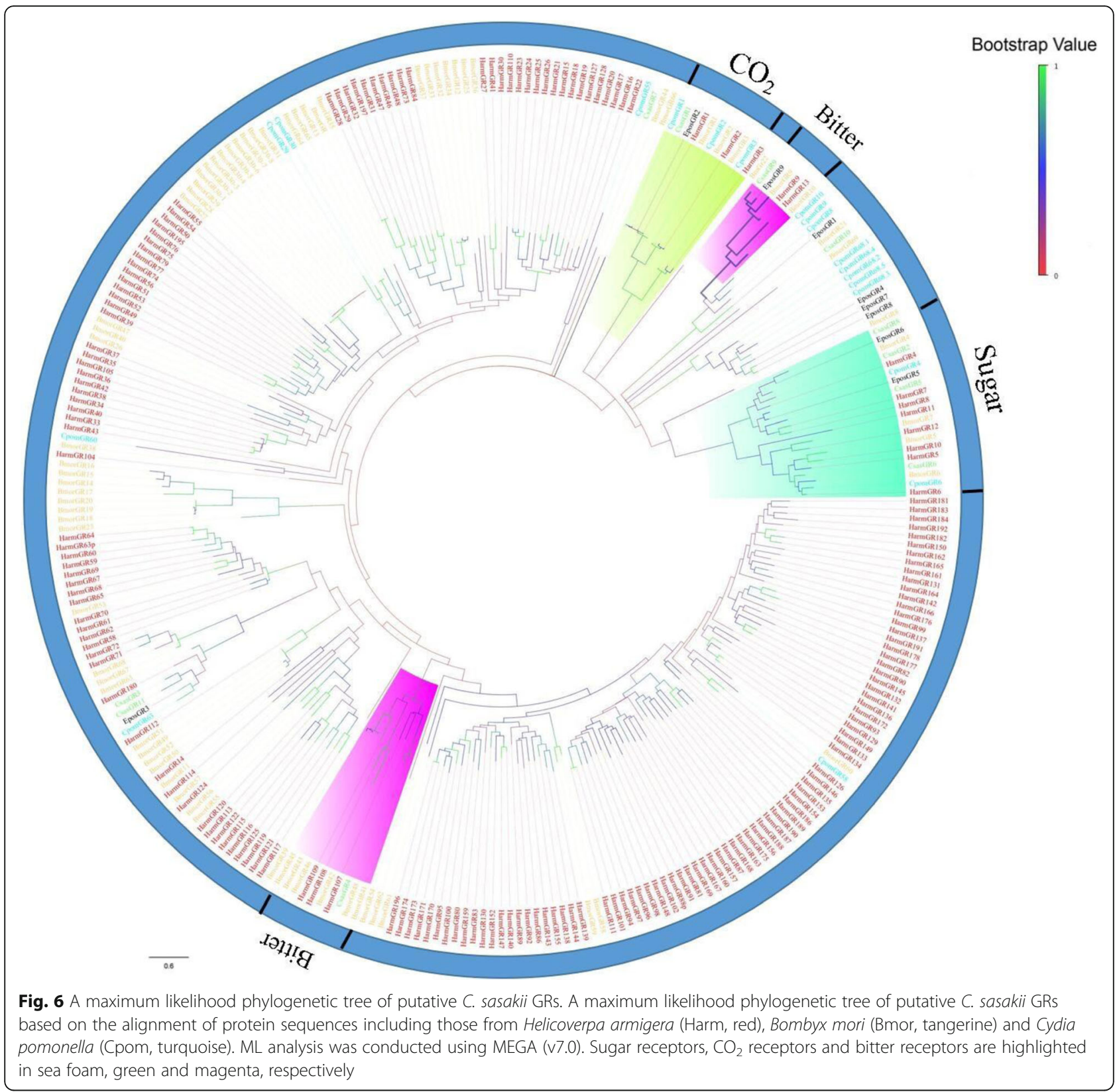

the results found in other insects, with 118 and 124 olfactory genes in Grapholita molesta and Hyphantria cunea, respectively $[65,66]$. In comparison to the transcriptome data from Eogystia hippophaecolus, the transcriptome data from C. sasakii contained fewer olfactory genes [67].

OBPs and CSPs have been considered to be the first step in the recognition of hydrophobic odors in the olfactory process. The number of OBPs identified in our antennal transcriptome was smaller than that in Epiphyas postvittana, Ostrinia furnacalis, and Bombyx mori $[61,68,69]$ but larger than that in Conogethes punctiferalis [70]. The qRT-PCR was used to explore the 12 of 29 OBPs of the expression files in different tissues based on the differential expression value analysis (FPKM), and the results revealed that most of them were primarily detected in antenna but not attributable exclusively to male and female antenna in $C$. sasakii, which confirmed the expression profile in other lepidopteran insects, such as $H$. assulta and Agrotis ipsilon [71, 72]. In addition, OBP7, GOBP1 and PBP2 exhibited highly abundant or biased obvious expression in male or female antennae in our observation, suggesting that these genes may play a vital role in antennal recognition processes. In comparison, CSPs showed high expression but no obvious expression bias in male and female antennae [73]. Moreover, the length of CSP3 was roughly twice that of the 

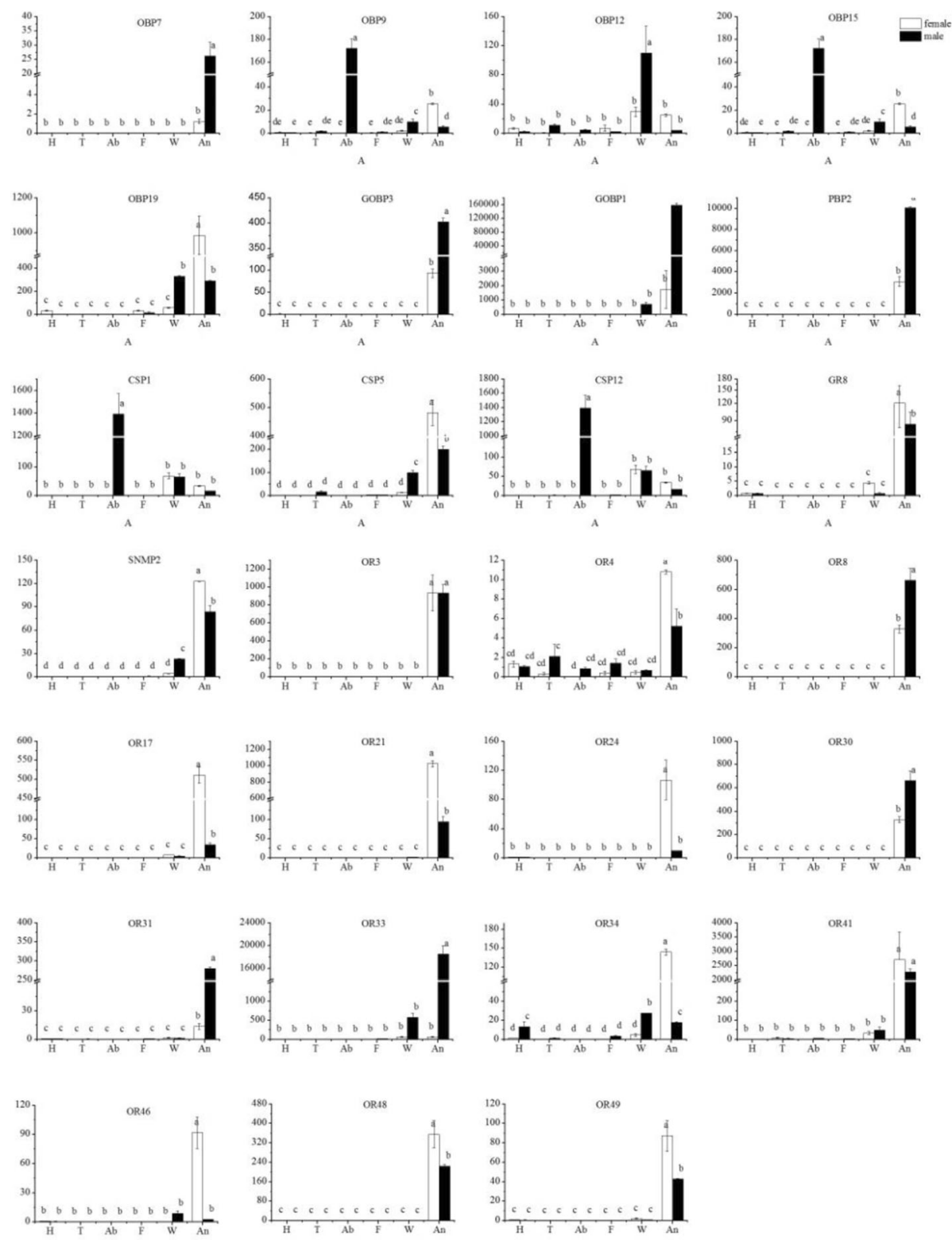

Fig. 7 Expression profiles of the candidate genes in different C. sasakii tissues. H: head; T: thorax; Ab: abdomen; F: foot; W: wing; A: antenna. Actin and EF-1a were used as the reference gene to normalize target gene expression. Black and white represents males and females, respectively. The standard errors are represented by the error bars; different lowercase letters $(a, b, c)$ above the bars denote significant differences at $p<0.05$

other CSPs, which was contrary to the general conclusion that chemosensory proteins were a class of binding proteins that are somewhat smaller than OBPs [31, 74]. Moreover, the amino acid sequence identity of CsasCSP3 with the other CSPs genes from Spodoptera exigua and Spodoptera litura was still as high as $60 \%$. Furthermore, CSP3 also exhibited the highly conserved four cysteines. In most moths, SNMP1 and SNMP2 are widely expressed in both the antennae and other body parts [75]. A previous study showed SNMP1 may be especially indispensable for the identification of volatiles or pheromones [76, 77]. While only SNMP2 was annotated, this indicated a further study was needed to identify the SNMP1. However, the high expression of CsasSNMP2 in males may be conducive to distinguishing its function in the antenna of male C. sasakii.

ORs located and expressed in olfactory sensory neurons play a crucial role in completing the process of odor signal reception and transduction [78-82]. Moth canonical chemosensory receptors (CRs) are comprised of three families of receptors: olfactory receptors (ORs), ionotropic receptors (IRs) or gustatory receptors (GRs) [83-85]. In our study, 52 ORs were detected. The results of the phylogenetic tree analysis showed that the 
candidate pheromone receptors (PRs) from $C$.sasakii and all of the PRs from different lepidopteran insects were clustered into the same clade in the tree, and the expression profiles of the candidate PRs showed that the expression of OR21 was extremely biased in female antennae when compared to the expression in male antennae, and the OR3 remained almost the same expression both male and female. This observation was contrary to the results that PRs were restricted to male antenna in Bombyx mori and other lepidopteran insects [86, 87]. In addition, some recent studies revealed that two PRs identified in $S$. littoralis were expressed in both sexes [88]. This observation may be consistent with theories that PBPs with female antenna-biased expression are responsible for detecting self-released sex pheromones [89-91]. Most of the ORs identified in other insects appear in pairs on the dendrogram [57, 92]. Specifically, among the five male-biased ORs, only the OR33 was clustered into the PR clade. However, beyond that, the qRT-PCR results indicated that the expression of OR33 in the male was nearly 30 times higher than that in the female. Accordingly, OR33 is most likely a PR.

Gustatory receptors (GRs) play critical roles in detecting taste chemicals, mating and finding oviposition sites [37, 93, 94]. Among all of the identified candidate GR transcripts, none appeared to be enriched in the male and female data set. Conversely, the FPKM of GRs indicated that the GRs had the lowest expression levels of all of the identified genes. In the phylogenetic analysis, the function of the CsasGRs was investigated by grouping these genes with other presumed GRs whose functions in the detection of a wide range of molecules including $\mathrm{CO}_{2}$, bitters, sugar compounds, including fructose have been studied explicitly. GR2, GR6, and GR8 were clustered into the sugar receptors lineages, suggesting that they likely play a role in tasting sugar. In addition, GR1 formed a clade with $\mathrm{CO}_{2}$ receptors, which meant the presence of GR1 in C. sasakii was likely to detect carbon dioxide, similar to in P. xylostella and B. mori $[95,96]$. In addition, this phenomenon that more of the CsasGRs found in the antennae transcriptome were clustered to sugar receptors may indicate that that they may perform an important function in sugar-detecting. In contrast, a large number of GRs have been identified in Helicoverpa armigera [97], which may be closely related to the host plant defense compounds but also the environment. The majority of GRs in insects showed high diversity, indicating that they were conducive to the specificity or expansion of taste detection [57].

Eight candidate IR genes were identified based on their similarities with other IRs in lepidopterans and physiologic analysis. Earlier studies have shown that IRs have a significant impact on the detection of amines and acids emitted during biological decomposition [81, 98, 99]. At present, IR8a and IR25a are commonly believed to be the co-receptor genes expressed in most of the coeloconic sensilla [81] and are assumed to have a similar function as co-receptor [63, 81]. Notably, co-receptors putatively encoding IR8a were found using BLASTx with reference to these transcripts and an ML tree. In addition, the lower expression level indicated by the FPKM analysis may account for the missing IRs. Other IRs belonged to the divergent IRs. Moreover, when compared to the IRs identified in Grapholita molesta, Cydia pomonella and Helicoverpa armigera, several conserved IRs of the same kind were identified [59, 67, 100-102]. Therefore, the number of IR genes expressed in antennal varied widely across different insects. Meanwhile, a variety of new IR groups have been proven to exist in different insects, such as Diptera $[67,103,104]$.

Finally, the tissue- and sex-specific expression analysis showed that the expression levels of 4 OBPs (OBP7, OBP 9, OBP12 and OBP15), 2 CSPs (CSP1 and CSP5), SNMP2 and 3 ORs (OR8, OR30 and OR41) were not consistent with the DEG analysis of their transcript abundances using FPKM values. In addition, OBP12 and CSP1 genes were detected at low levels by transcriptome sequencing projects, but the results performed by qPCR showed that they were abundantly expressed in other tissues of the adult male and female. These differences in the qPCR and RNA-Seq results may be the consequence of the greater sensitivity of qPCR compared to that of RNA-Seq in the male and female antennae, given the depth at which these genes were sequenced. In addition, this sensitivity difference likely also accounts for why fewer IR gene transcripts were detected in the male and female antenna using RNA-Seq.

\section{Conclusion}

The peach fruit moth is regarded as a major invasive fruit-boring pest affecting various fruit trees. However, the olfactory system of the peach fruit moth has not been deciphered as of yet. In our study, the six main olfactory gene families encoding proteins with vital roles in chemoreception were annotated. Although many olfactory genes remain to be identified in this transcriptome compared with the identified genes in other transcriptomes, this study fills our gap in knowledge of the olfactory system in C. sasakii. Then, we classified the olfactory genes based on their conservation, predicted transmembrane domains and phylogenetic analysis. Then, sex-biased expression levels of the differentially expressed genes were observed in the transcriptomic data and validated by RT-qPCR. The expression profile analysis revealed that 7 OBPs, 3 CSPs, 1 SNMP, 14 ORs and 2 GRs were uniquely or primarily expressed in the different tissues examined of males and females. Our research offers 
context and basic foundations for the future identification of the concrete molecular mechanisms of olfaction in $C$. sasakii. Further studies of olfactory function will provide comprehensive methods and original strategies for integrated pest management (IPM).

\section{Additional files}

Additional file 1: Amino acid sequences of all candidate chemosensory proteins identified in the C. sasakii transcriptome. (DOCX $37 \mathrm{~kb}$ )

Additional file 2: Amino acid sequences used in phylogenetic trees. (DOCX $196 \mathrm{~kb}$ )

Additional file 3: Primers designed for fluorescence quantitative realtime PCR. (XLSX $12 \mathrm{~kb})$

Additional file 4: Figures S1-S3. (DOCX $1489 \mathrm{~kb})$

Additional file 5: BLASTX annotation against the NCBI non-redundant protein database for putative olfactory genes. (XLSX $35 \mathrm{~kb}$ )

Additional file 6: Expression levels of candidate olfactory receptors measured in the RNA-Seq analysis. (XLSX $58 \mathrm{~kb}$ )

\section{Abbreviations}

CSPs: Chemosensory proteins; DEG: Differentially expressed genes; FPKM: Fragments per kilobase per million reads; GO: Gene ontology; GPCRs: G protein-coupled receptors; GRs: Gustatory receptors; IPM: Integrated pest management; IRs: Ionotropic receptors; NGS: Nextgeneration sequencing; OBPs: Odorant-binding proteins; Orco: Odorant receptor co-receptor; ORF: Open reading frame; ORN: Olfactory receptor neuron; ORs: Odorant receptors; PR: Pheromone receptor; SNMPs: Sensory neuron membrane proteins

\section{Acknowledgements}

We thank Biomake Company for providing technical support in next-generation sequencing.

\section{Funding}

The research was supported by the National Natural Science Foundation of China No. 31601643 and Fundamental Research Funds for Central Non-Profit Scientific Institution No. 1610182016004.

\section{Availability of data and materials}

All supporting data are included within the article and its additional files, and the raw data were submitted to NCBI with the submission number SRR5431770 and SRR5431771. In addition, all contigs have been submitted to the Transcriptome Shotgun Assembly (TSA) sequence database at NCBI with the accession numbers GFQL00000000. Finally, all of the genes related to this study were also submitted with accession numbers MG546553 to MG546666.

\section{Authors' contributions}

ZQT carried out the molecular genetic studies, performed the sequence alignment and drafted the manuscript. LNS and YYL participated in the bioinformatic analysis and the sequence alignment. GSQ, LNS, YYL and HJZ participated in the design of the study and performed the statistical analysis. LFQ, WTY and QY collected almost all of the samples and participated in some experiments. LNS and YYL also helped to draft the manuscript. All authors read and approved the final manuscript.

\section{Authors' information}

Zhiqiang Tian: master candidate; major: plant protection; study direction: agricultural entomology and pest control.

Lina Sun: associate professor; study direction: insect molecular biology. Yanyan Li: PhD; study direction: insect molecular biology.

Linfa Quan: master candidate; major: plant protection; study direction: agricultural entomology and pest control.

Huaijiang Zhang: associate professor; study direction: insect molecular biology.
Wentao Yan: assistant professor; study direction: insect ecology. Qiang Yue: assistant professor; study direction: agricultural entomology and pest control.

Guisheng Qiu: professor; study direction: agricultural entomology and pest control.

\section{Ethics approval and consent to participate}

The peach fruit moth, Carposina sasakii Matsumura (Lepidoptera: Carposinidae), poses a serious threat to a variety of fruits and causes significant economic losses owing to its difficult prevention. This species is not included in the "List of Endangered and Protected Animals in China". All operations were performed according to ethical guidelines in order to minimize pain and discomfort to the insects.

\section{Consent for publication}

Not applicable.

\section{Competing interests}

The authors declare that they have no competing interests.

\section{Publisher's Note}

Springer Nature remains neutral with regard to jurisdictional claims in published maps and institutional affiliations.

Received: 13 December 2017 Accepted: 26 June 2018

Published online: 20 July 2018

\section{References}

1. Ma G, Tian BL, Zhao F, Wei GS, Hoffmann AA, Ma CS. Soil moisture conditions determine phenology and success of larval escape in the peach fruit moth, Carposina sasakii, (Lepidoptera, Carposinidae): implications for predicting drought effects on a diapausing insect. Appl Soil Ecol. 2017;110:65-72.

2. Quan LF, Qiu GS, Zhang HJ, Sun LN, Li YY, Yan WT, et al. Sublethal concentration of beta-cypermethrin influences fecundity and mating behavior of Carposina sasakii (Lepidoptera: Carposinidae) adults. J Econ Entomol. 2016;109(5):tow170.

3. Zhan G, Li B, Gao M, Liu B, Wang Y, Liu T, et al. Phytosanitary irradiation of peach fruit moth (Lepidoptera: Carposinidae) in apple fruits. Radiat Phys Chem. 2014;103(5):153-7.

4. Zhang YL, Mu W, Chen ZL, et al. Susceptibility and related physiological and biochemical mechanisms of Carposina niponensis Walsingham larvae on six insecticides before and after overwintering. Chin J Appl Ecol. 2007;18(8): 1913-6. (in Chinese)

5. Ge LQ, Wu JC, Zhao KF, et al. Induction of Nlvg, and suppression of Nljhe, gene expression in Nilaparvata lugens, (Stål) (Hemiptera: Delphacidae) adult females and males exposed to two insecticides. Pestic Biochem Phys. 2010; 98(2):269-78.

6. Downes $\mathrm{S}$, Kriticos $\mathrm{D}$, Parry $\mathrm{H}$, et al. A perspective on management of Helicoverpa armigera: transgenic Bt cotton, IPM, and landscapes. Pest Manag Sci. 2016;73(3):485-92.

7. Mushtaq A, Hollingworth RM, Wise JC. Broad-spectrum insecticide resistance in obliquebanded leafroller Choristoneura rosaceana (Lepidoptera: Tortricidae) from Michigan. Pest Manag Sci. 2002;58(8):834.

8. Chai RY, Lee CY. Insecticide resistance profiles and synergism in field populations of the German cockroach (Dictyoptera: Blattellidae) from Singapore. J Econo Entomol. 2010;103(2):460.

9. Field LM, Pickett JA, Wadhams LJ. Molecular studies in insect olfaction. Insect Mol Biol. 2000;9(6):545-51.

10. Smadja C, Butlin RK. On the scent of speciation: the chemosensory system and its role in premating isolation. Heredity. 2009;102(1):77-97.

11. Tamaki Y, Honma K, Kawasaki K. Sex pheromone of the peach fruit moth, Carposina niponensis Walsingham (Lepidoptera: Carposinidae): isolation, identification and synthesis. Appl Entomol Zool. 1977;12:60-8.

12. Yuvaraj JK, Corcoran JA, Andersson MN, et al. Characterization of odorant receptors from a non-ditrysian moth, Eriocrania semipurpurella sheds light on the origin of sex pheromone receptors in Lepidoptera. Mol Biol Evol. 2017;34(11):2733-46.

13. Zhang DD, Löfstedt C. Moth pheromone receptors: gene sequences, function, and evolution. Front Ecol Evol. 2015;3:105. 
14. Ando T, Inomata S, Yamamoto M. Lepidopteran sex pheromones. Top Curr Chem. 2004;239:51.

15. Han KS, Jin KJ, Choi KH, et al. Sex pheromone composition and male trapping of the peach fruit moth, Carposina sasakii (Matsumura) (Lepidoptera: Carposinidae) in Korea. J Asia Pac Entomo. 2000;3(2):83-8.

16. Montagné et al., 2015, Book chapter in progress in molecular biology and translational science, volume 130, "Molecular basis of olfaction".

17. Gong TR, Li XG, Yang LJ, Zhang X. Ultrastructural observation antennal sensilla of Carposina niponensis Walsingham (Lepidoptera: Carposinidae). J Northwest A\&F Univ (Nat Sci Ed). 2012;40(6):120-4. (In Chinese)

18. Liu Z, Hua BZ, Liu L. Ultrastructure of the sensilla on larval antennae and mouthparts in the peach fruit moth, Carposina sasakii Matsumura (Lepidoptera: Carposinidae). Micron. 2011;42(5):478-83.

19. Jiang TX, Lu Y, Yan L, et al. Ultrastructures of sensilla on pseud ovipositor of Carposina sasakii. Guizhou Agr Sci. 2016;44(4):57-9. (In Chinese)

20. Sun $Y T$, Wang $H P$, Workstation $L T$. Electroantennograms activities of Carposina sasakii Matsumura to volatiles of apples. Liaoning Agr Sci. 2015, 2: 11-3. (in Chinese) Zhang J, Walker W B, Wang G R. Pheromone reception in moths: from molecules to behaviors. Prog Mol Biol Transl Sci. 2015, 130: 109-28.

21. Fan J, Francis F, Liu Y, Chen JL, Cheng DF. An overview of odorant-binding protein functions in insect peripheral olfactory reception. GMR. 2011;10(4): 3056-69.

22. Pelosi P, Zhou JJ, Ban L, Calvello M. Soluble proteins in insect chemical communication. Cell Mol Life Sci. 2006;63(14):1658-76.

23. Wang R, Zhang XM, Li HL, Guo XJ, Luo C. Identification and expression profiling of five chemosensory protein genes in the whitefly med. J Asia-Pac Entomol. 2016;19(1):195-201.

24. Sun $H$, Song $Y$, Du J, Wang $X$, Cheng Z. Identification and tissue distribution of chemosensory protein and odorant binding protein genes in Athetis dissimilis, (Lepidoptera: Noctuidae). Appl Entomol Zool. 2016;51(3):409-20.

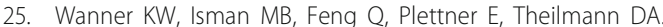
Developmental expression patterns of four chemosensory protein genes from the eastern spruce budworm, Chroistoneura fumiferana. Insect Mol Biol. 2005;14(3):289-300.

26. Jacquin-Joly E, Vogt RG, François MC, Meillour NL. Functional and expression pattern analysis of chemosensory proteins expressed in antennae and pheromonal gland of Mamestra brassicae. Chem Senses. 2001;26(7):833-44

27. Liu R, He X, Lehane S, Lehane M, Hertz-Fowler C, Berriman M, et al. Expression of chemosensory proteins in the tsetse fly Glossina morsitans is related to female host-seeking behaviour. Insect Mol Biol. 2012;21:41-8.

28. Bohbot J, Sobrio F, Lucas P, Meillour NL. Functional characterization of a new class of odorant-binding proteins in the moth Mamestra brassicae. Biochem Biophys Res Commun. 1998:253(2):489-94.

29. Nomura A, Kawasaki K, Kubo T, et al. Purification and localization of p10, a novel protein that increases in nymphal regenerating legs of Periplaneta americana (American cockroach). Int J Dev Biol. 1992;36(3):391-8.

30. Guo W, Wang X, Ma Z, et al. CSP and takeout genes modulate the switch between attraction and repulsion during behavioral phase change in the migratory locust. PLoS Genet. 2011;7(2):e1001291.

31. Sánchezgracia A, Vieira FG, Rozas J. Molecular evolution of the major chemosensory gene families in insects. Heredity. 2009;103(3):208-16.

32. Forstner M, Gohl T, Gondesen I, Raming K, Breer H, Krieger J. Differential expression of SNMP-1 and SNMP-2 proteins in pheromone-sensitive hairs of moths. Chem Senses. 2008;33:291-9.

33. Vosshall $L$, Amrein $H$, Morozov PS, Rzhetsky A. Axel R. A spatial map of olfactory receptor expression in the Drosophila antenna. Cell. 1999;96(5):725-36.

34. Hildebbrand JG. Olfactory control of behavior in moths: central processing of odor information and the functional significance of olfactory glomeruli. J Comp Physiol A. 1996;178(1):5-19.

35. Clyne P, Warr C, Freeman M, Lessing D, Kim JC. A novel family of divergent seven-transmembrane proteins: candidate odorant receptors in Drosophila. Neuron. 1999;22:327-38.

36. Benton R, Sachse S, Michnick SW, Vosshall LB. Atypical membrane topology and heteromeric function of Drosophila odorant receptors in vivo. PLoS Biol. 2006:4(2):240-57.

37. Clyne PJ, Warr CG, Carlson JR. Candidate taste receptors in Drosophila. Sci. 2000;287(5459):1830-4.

38. Gillies MT. The role of carbon dioxide in host-finding by mosquitoes (Diptera: Culicidae): a review. B Entomol Res. 1980;70(4):525-32.
39. Erdelyan CN, Mahood TH, Bader TS, et al. Functional validation of the carbon dioxide receptor genes in Aedes aegypti mosquitoes using RNA interference. Insect Mol Biol. 2012;21(1):119-27.

40. Mayer ML. Emerging models of glutamate receptor ion channel structure and function. Structure. 2011;19(10):1370.

41. Rytz R, Croset V, Benton R. Ionotropic receptors (IRs): chemosensory ionotropic glutamate receptors in Drosophila and beyond. Insect Bio Molecular Biol. 2013;43(9):888-97.

42. Xue YH, Ma RY, Li XW, Li L, Li J. Research and application on the sex pheromone of Carposina sasakii Matsumura (Lepidoptera: Carposinidae). Chin J Biol Control. 2010;26(2):211-6. (in Chinese)

43. Grabherr MG, Haas BJ, Yassour M, Levin JZ, Thompson DA, Amit I, et al. Full length transcriptome assembly from RNA Seq data without a reference genome. Nat Biotechol. 2011;29(7):644-52.

44. Eddy SR. Profile hidden Markov models. Bioinformatics. 1998;14(9):755-63.

45. Finn RD, Bateman A, Clements J, Coggill P, Eberhardt RY, Eddy SR, et al. Pfam: the protein families database. Nucleic Acids Res. 2014;42(Database issue):D222

46. Conesa A, Götz S, García-Gómez JM, Terol J, Talón M, Robles M. Blast2GO: a universal tool for annotation, visualization and analysis in functional genomics research. Bioinformatics. 2005;21(18):3674-6.

47. Pertea G. Transcript assembly and quantification by RNA Seq reveals unannotated transcripts and isoform switching during cell differentiation. Nature Biotechnol. 2010;28(5):511-5.

48. Quevillon E, Silventoinen V, Pillai S, Harte N, Mulder N, Apweiler R, et al. InterProScan: protein domains identifier. Nucleic Acids Res. 2005;33(Web Server issue):W116-20.

49. Kumar S, Stecher G, Tamura K. MEGA7 Molecular evolutionary genetics analysis version 7.0 for bigger datasets. Mol Biol Evol. 2016;33(7):1870-4

50. Guo W, Rao B. On optimality of the Benjamini-Hochberg procedure for the false discovery rate. Stat Probabil Lett. 2008;78(14):2024-30.

51. Pelosi $P$, Maida R. Odorant-binding proteins in insects. Comp Biochem Physiol B Biochem Mol Biol. 1995;111(3):503-14.

52. Vieira FG, Rozas J. Comparative genomics of the odorant-binding and chemosensory protein gene families across the Arthropoda: origin and evolutionary history of the chemosensory system. Genome Biol Evol. 2011; 3(1):476-90

53. Zhou JJ, He XL, Pickett JA, Field LM. Identification of odorant binding proteins of the yellow fever mosquito Aedes aegypti: genome annotation and comparative analyses. Insect Mol Biol. 2008;17:147-63.

54. Zhou JJ, Kan Y, Antoniw J, Pickett JA, Field LM. Genome and EST analyses and expression of a gene family with putative functions in insect chemoreception. Chem Senses. 2006;31(5):453-65.

55. Angeli S, Ceron F, Scaloni A, Monti M, Monteforti G, Minnocci A, et al. Purification, structural characterization, cloning and immunocytochemical localization of chemoreception proteins from Schistocerca gregaria. Eur J Biochem. 1999;262(3):745-54

56. Cheng J, Wang CY, Lyu ZH, Chen JX, Lin T. De novo assembly and identification of antennal transcriptome reveals an olfactory system in Heortia vitessoides (Lepidoptera: Crambidae). PeerJ Preprints. 2017;20(4): $1241-8$.

57. Ge X, Zhang TT, Wang ZY, He KL, Bai S. Identification of putative chemosensory receptor genes from yellow peach moth Conogethes punctiferalis (guenée) antennae transcriptome. Sci Rep. 2016;6:32636.

58. Patch HM, Velarde RA, Walden KKO. Robertson HM. a candidate pheromone receptor and two odorant receptors of the Hawkmoth Manduca sexta. Chem Senses. 2009;34(4):305.

59. Walker WB III, Gonzalez F, Garczynski SF, et al. The chemosensory receptors of codling moth Cydia pomonella-expression in larvae and adults. Sci Rep. 2016;6:23518.

60. Sakurai T, Nakagawa T, Mitsuno $H$, Mori H, Endo $Y$, Tanoue $S$, et al. Identification and functional characterization of a sex pheromone receptor in the silkmoth Bombyx mori. PNAS. 2004;101(47):16653-8.

61. Corcoran JA, Jordan MD, Thrimawithana AH, et al. The peripheral olfactory repertoire of the Lightbrown apple moth, Epiphyas postvittana. PLoS One. 2015;10(5):e0128596.

62. Krieger J, Grosse-Wilde E, Gohl T, et al. Genes encoding candidate pheromone receptors in a moth (Heliothis virescens). PNAS. 2004; 101(32):11845.

63. Abuin $\mathrm{L}$, Bargeton $\mathrm{B}$, Ulbrich $\mathrm{MH}$, et al. Functional architecture of olfactory ionotropic glutamate receptors. Neuron. 2011;69(1):44-60. 
64. Dong J, Song Y, Li W, et al. Identification of putative chemosensory receptor genes from the Athetis dissimilis antennal transcriptome. PLoS One. 2016; 11(1):e0147768.

65. Li G, Du J, Li Y. Wu J. Identification of putative olfactory genes from the oriental fruit moth Grapholita molesta via antennal transcriptome analysis. PLoS One. 2015;10(11):e0142193.

66. Zhang LW, Kang K, Jiang SC, Zhang YN, Wang TT, Zhang J, et al. Analysis of the antennal transcriptome and insights into olfactory genes in Hyphantria cunea(drury). PLoS One. 2016;11(10):e0164729.

67. Hu P, Tao J, Cui M, Gao C, Lu P, Luo Y. Antennal transcriptome analysis and expression profiles of odorant binding proteins in Eogystia hippophaecolus (Lepidoptera: Cossidae). BMC Genomics. 2016;17(1):651.

68. Paula DP, Togawa RC, Costa MMC, Grynberg P, Martins NF, Andow DA, et al. Identification and expression profile of odorant-binding proteins in Halyomorpha halys, (Hemiptera: Pentatomidae). Insect Mol Biol. 2016;25(5):580-94.

69. Gong DP, Zhang HJ, Zhao P, Xia QY, Xiang ZH. The odorant binding protein gene family from the genome of silkworm. BMC Genomics. 2009;10(1):332

70. Jia XJ, Wang HX, Yan ZG, Zhang MZ, Wei CH, Qin XC, et al. Antennal transcriptome and differential expression of olfactory genes in the yellow peach moth, Conogethes punctiferalis (Lepidoptera: Crambidae). Sci Rep. 2016;6:29067.

71. Zhang J, Wang B, Dong S, Cao D, Dong J, Walker WB, et al. Antennal transcriptome analysis and comparison of chemosensory gene families in two closely related noctuidae moths, Helicoverpa armigera and $\mathrm{H}$. assulta. PLoS One. 2015;10(2):e0117054.

72. Gu SH, Sun L, Yang RN, Wu KM, Guo YY, Li XC, et al. Molecular characterization and differential expression of olfactory genes in the antennae of the black cutworm moth Agrotis ipsilon. PLoS One. 2014; 9(8):e103420.

73. Zhang YN, Jin JY, Jin R, Xia YH, Zhou JJ, Deng JY, et al. Differential expression patterns in chemosensory and non-chemosensory tissues of putative chemosensory genes identified by transcriptome analysis of insect pest the purple stem borer Sesamia inferens(Walker). PLoS One. 2013;8(7):e69715.

74. Vogt RG. Biochemical diversity of odor detection: OBPS, ODEs and SNMPs. Insect pheromone biochemistry and molecular biology. San Diego: Academic Press; 2003. p. 391-445.

75. Robertson HM, Warr CG, Carlson JR. Molecular evolution of the insect chemoreceptor gene superfamily in Drosophila melanogaster. PNAS. 2003; 100(Suppl 2):14537.

76. Vogt RG, Miller NE, Litvack R, et al. The insect SNMP gene family. Insect Biochem Mol Biol. 2009;39(7):448-56.

77. Benton R, Vannice K, Vosshall LB. An essential role for a CD36-related receptor in pheromone detection in Drosophila. Nature. 2007;450(7167):289-93.

78. Jin X, Ha TS, Smith DP. SNMP is a signaling component required for pheromone sensitivity in Drosophila. PNAS. 2008;105(31):10996-1001.

79. MDe B, Baker TC. Odor detection in insects: volatile codes. J Chem Ecol. 2008;34(7):882-97.

80. Scott K, Brady R Jr, Cravchik A, Morozov P, Rzhetsky A, Zuker C, et al. A chemosensory gene family encoding candidate gustatory and olfactory receptors in Drosophila. Cell. 2001;104(5):661.

81. Benton R, Vannice KS, Gomez-Diaz C, Vosshall LB. Variant ionotropic glutamate receptors as chemosensory receptors in Drosophila. Cell. 2009; 136(1):149-62

82. Sato K, Touhara K. Insect olfaction: receptors, signal transduction, and behavior. Results Probl Cell Differ. 2009;47:121-38.

83. Koenig C, Hirsh A, Bucks S, Klinner C, Vogel H, Shukla A, et al. A reference gene set for chemosensory receptor genes of Manduca sexta. Insect Biochem Mol Biol. 2015;66:51-63.

84. Cande J, Prud'homme B, Gompel N. Smells like evolution: the role of chemoreceptor evolution in behavioral change. Curr Opin Neurobiol. 2013;23:152-8.

85. Nei M, Niimura Y, Nozawa M. The evolution of animal chemosensory receptor gene repertoires: roles of chance and necessity. Nat Rev Genet. 2008;9:951-63.

86. Mitsuno H, Sakurai T, Murai M, Yasuda T, Kugimiya S, Ozawa R, et al. Identification of receptors of main sex-pheromone components of three lepidopteran species. Eur J Neurosci. 2008;28:893-902.

87. Cao D, Liu Y, Wei J, Liao X, Walker WB, Li J, et al. Identification of candidate olfactory genes in Chilo suppressalis by antennal transcriptome analysis. Int $J$ Biol Sci. 2014;10(8):846.
88. Legeai F, Malpel S, Montagne N, Monsempes C, et al. An expressed sequence tag collection from the male antennae of the noctuid moth Spodoptera littoralis: a resource for olfactory and pheromone detection research. BMC Genomics. 2011;12:86.

89. Mayhew PJ. Herbivore host choice and optimal bad motherhood. Trends Ecol Evol. 2001;16(4):165-7.

90. Scheirs J, Bruyn LD. Integrating optimal foraging and optimal oviposition theory in plant-insect research. Oikos. 2002;96(1):187-91.

91. Naoyuki F, Chiharu T, Michiko A, Haruo K. Oviposition site selection by herbivorous beetles: a comparison of two thistle feeders, Cassida rubiginosa and Henosepilachna niponica. Entomol Exp Appl. 2008:128(1):41-8.

92. Engsontia P, Sangket U, Chotigeat W, Satasook C. Molecular evolution of the odorant and gustatory receptor genes in lepidopteran insects: implications for their adaptation and speciation. J Mol Evol. 2014;79(1):21-39.

93. Freeman EG, Wisotsky Z, Dahanukar A. Detection of sweet tastants by a conserved group of insect gustatory receptors. PNAS. 2014;111(4):1598-603.

94. Wanner KW, Robertson HM. The gustatory receptor family in the silkworm moth Bombyxmori is characterized by a large expansion of a single lineage of putative bitter receptors. Insect Mol Biol. 2008;17(6):621-9.

95. Jones WD, Cayirlioglu P, Kadow IG, Kadow LG, Vosshall LB. Two chemosensory receptors together mediate carbon dioxide detection in Drosophila. Nature. 2007:445(7123):86-90.

96. Robertson HM, Kent LB. Evolution of the gene lineage encoding the carbon dioxide receptor in insects. J Insect Sci. 2009;9(19):1-14.

97. Xu W, Alexie P, Zhang HJ, et al. Expansion of a bitter taste receptor family in a polyphagous insect herbivore. Sci Rep. 2016;6:23666.

98. Cooke M, Leeves N, White C. Time profile of putrescine, cadaverine, indole and skatole in human saliva. Arch Oral Biol. 2003:48(4):323-7.

99. Vass AA, Smith RR, Thompson CV, Burnett MN, Dulgerian N, Eckenrode BA. Odor analysis of decomposing buried human remains. J Forensic Sci. 2008; 53(2):384-91.

100. Li G, Du J, Li Y, et al. Identification of putative olfactory genes from the oriental fruit moth Grapholita molesta via an antennal transcriptome analysis. PLoS One. 2015;10(11):e0142193.

101. Bengtsson JM, Trona F, Montagné $\mathrm{N}$, et al. Putative chemosensory receptors of the codling moth, Cydia pomonella, identified by antennal transcriptome analysis. PLoS One. 2012;7(2):e31620.

102. Liu Y, Gu S, Zhang Y, Guo Y, Wang G. Candidate olfaction genes identified within the Helicoverpa armigera antennal transcriptome. PLoS One. 2012; 7(10):e48260.

103. Croset V, Rytz R, Cummins SF, Budd A, Brawand D, Kaessmann H, Gibson TJ, Benton R. Ancient protostome origin of chemosensory ionotropic glutamate receptors and the evolution of insect taste and olfaction. PLoS Genet. 2010:6(8):e1001064-10.

104. Bv S, Jiggins CD, Briscoe AD, Papa R. Genome-wide analysis of ionotropic receptors provides insight into their evolution in Heliconius butterflies. BMC Genomics. 2016;17(1):1-5.

\section{Ready to submit your research? Choose BMC and benefit from:}

- fast, convenient online submission

- thorough peer review by experienced researchers in your field

- rapid publication on acceptance

- support for research data, including large and complex data types

- gold Open Access which fosters wider collaboration and increased citations

- maximum visibility for your research: over $100 \mathrm{M}$ website views per year

At BMC, research is always in progress.

Learn more biomedcentral.com/submissions 